\title{
THE ANTITHROMBOTIC EFFECT OF APROTININ: ACTIONS MEDIATED VIA THE PROTEASE- ACTIVATED RECEPTOR 1
}

\author{
Michael Poullis, FRCS ${ }^{\mathrm{a}}$ \\ Richard Manning, BSc ${ }^{\mathrm{b}}$ \\ Mike Laffan, FRCP \\ Dorian O. Haskard, FRCP \\ Kenneth M. Taylor, FRCS ${ }^{\text {a }}$ \\ R. Clive Landis, $\mathrm{PhD}^{\mathrm{c}}$
}

\begin{abstract}
Background: Despite aprotinin being in widespread clinical use to prevent bleeding during cardiac surgery, there remains concern that such a powerful hemostatic agent may also be prothrombotic, particularly in relation to coronary vein graft occlusion. The major thrombin receptor on platelets, protease-activated receptor 1 (PAR1) requires proteolytic cleavage to transmit activating signals. Here we have investigated the effect of aprotinin on thrombin-induced PAR1 activation of platelets.
\end{abstract}

Methods and results: Proteolysis-dependent and -independent responses of washed platelets were studied in vitro. Platelet aggregation induced by trypsin was dependent on PAR1 (inhibited by the PAR1-specific antagonist peptide, FLLRN) and was completely blocked by aprotinin at doses more than $100 \mathrm{KIU} / \mathrm{mL}$. Aggregation in response to thrombin, $1 \mathrm{nmol} / \mathrm{L}$, was predominantly mediated through PAR1 and was inhibited $42.6 \%$ to $86.6 \%(P<$ $.05-.001)$ by pharmacologic doses of aprotinin (50-160 KIU/mL). Aprotinin did not inhibit the nonproteolytic agonists collagen, epinephrine, adenosine diphosphate, or phorbol 12-myristate 13-acetate. Furthermore, blockade of the thrombin response by aprotinin did not prevent subsequent platelet aggregation through collagen or epinephrine. Experiments with intraplatelet $\mathrm{Ca}^{2+}$ fluxes, which provided an earlier measure of platelet activation, placed the effect of aprotinin proximal to the PAR1 activation event. Since aprotinin did not inhibit platelet responses to the nonproteolytic PAR1 agonist peptide, SFLLRN, this implied that aprotinin acted by preventing PAR1 receptor cleavage by thrombin.

Conclusions: Aprotinin inhibits thrombin-induced platelet activation by preventing proteolysis of the PAR1 receptor. These findings argue against aprotinin being prothrombotic and suggest instead that aprotinin may have significant antithrombotic effects. (J Thorac Cardiovasc Surg 2000;120:370-8)
$\mathrm{P}$ ostoperative bleeding is an ever-present concern of cardiac surgeons. Aprotinin (Trasylol; Bayer AG, Leverkusen, Germany) is in widespread clinical use for its ability to reduce blood loss and preserve platelet function after cardiopulmonary bypass. ${ }^{1-5}$ The mechanism of action of aprotinin on the platelet, however, has remained uncertain since the first demonstration of its hemostatic properties 12 years ago. ${ }^{1,2}$ This

From the BHF Units of Cardiothoracic Surgery ${ }^{\mathrm{a}}$ and Cardiovascular Medicine, ${ }^{\mathrm{b}}$ National Heart and Lung Institute, and the Department of Haematology, ${ }^{\mathrm{c}}$ Hammersmith Hospital, Imperial College School of Medicine, London, United Kingdom.

Supported by grants from the British Heart Foundation and GlaxoWellcome PLC.

Received for publication Feb 7, 2000; revisions requested April 11, 2000; revisions received May 4, 2000; accepted for publication May 11, 2000. uncertainty has contributed to the concern that aprotinin may be implicated in causing coronary graft occlusion because of its powerful hemostatic effects. ${ }^{6,7}$ This remains a controversial issue, however, as numerous other trials have not identified a clinical association between aprotinin use and graft occlusion in coronary artery bypass surgery. ${ }^{8}$ In this study, we have directly addressed in vitro the question whether

\footnotetext{
Address for reprints: R. Clive Landis, PhD, BHF Cardiovascular Medicine Unit, National Heart and Lung Institute, Imperial College School of Medicine, Hammersmith Hospital, Du Cane Road, London W12 0NN, United Kingdom (E-mail: r.landis@ic.ac.uk).

Copyright (C) 2000 by The American Association for Thoracic Surgery

0022-5223/2000 $\$ 12.00+0 \quad \mathbf{1 2} / \mathbf{1} / \mathbf{1 0 8 5 3 1}$

doi:10.1067/mtc.2000.108531
} 
aprotinin can influence thrombin-induced platelet activation.

Thrombin plays a central role in the hemostatic response to cardiopulmonary bypass. Its generation in response to the bypass circuit is of great concern to cardiac surgeons and is associated with platelet dysfunction, excessive bleeding, and an increased incidence of graft occlusion. ${ }^{9-12}$ The major thrombin receptor on platelets is protease-activated receptor 1 (PAR1), a 7transmembrane receptor and member of the $G$ protein-coupled superfamily of receptors. ${ }^{13}$ In common with other $G$ protein-coupled receptors, PAR1 responds to the binding of ligand by transducing a heterotrimeric $G$ protein-coupled signal into the cell, resulting in a $\mathrm{Ca}^{2+}$ flux and cellular activation. ${ }^{14}$ However, a unique feature of PAR1 and the 3 other members of the PAR subfamily (PARs 1-4) is a requirement for proteolytic cleavage to generate the intracellular signal. ${ }^{13,15}$ PAR1 activation by thrombin involves initial binding to a hirudin-like domain (amino acids 53-64) of the receptor followed by proteolytic cleavage between arginine-41 and serine- $42 .{ }^{16}$ Cleavage of PAR1 is via the serine protease activity of thrombin, which may be mimicked at lower efficiency by other unrelated serine proteases, such as trypsin. Proteolytic cleavage unmasks a tethered ligand that interacts with sequences corresponding to extracellular loop 2 of PAR1, which in turn transduces heterotrimeric G protein-coupled intracellular responses. ${ }^{17}$ Many of the native responses of thrombin can be reproduced by a synthetic PAR1 agonist peptide, SFLLRN, which simulates the action of tethered ligand but critically does not require proteolysis of the receptor. ${ }^{18,19}$

In addition to PAR1, platelets possess other thrombin receptors, including PAR4 and glycoprotein $\mathrm{Ib}{ }^{20,21}$ The PAR1 component of the platelet response to thrombin or other PAR receptor agonists, such as SFLLRN or trypsin, can be defined in vitro through the use of PAR1-specific antagonistic peptides that competitively block the binding of tethered ligand and thereby prevent receptor activation. ${ }^{18,22}$ In the present article, we have used such peptides to initially define in washed platelets the PAR1 dependence of platelet activation in response to thrombin and trypsin. We then tested the hypothesis that aprotinin, as a broad-spectrum serine protease inhibitor, might inhibit proteolytic signaling via PAR1 and downstream platelet responses to the agonists thrombin and trypsin. As a control, we compared the effect of aprotinin on proteolysis-independent pathways of platelet activation, including the use of agonists SFLLRN, collagen, epinephrine, adenosine diphosphate (ADP), and phorbol 12-myristate 13- acetate (PMA). Our results show that aprotinin specifically inhibited thrombin and trypsin-induced platelet activation by blocking the proteolytic cleavage of PAR1.

\section{Materials and methods}

Reagents. Collagen, thrombin, trypsin, and aprotinin were obtained from Sigma Diagnostics (Poole, United Kingdom). The PAR1 agonist peptide, SFLLRN, was obtained from Bachem UK Ltd (Saffron Walden, United Kingdom). PAR1 antagonist peptide, FLLRN, was synthesized by the Advanced Biotechnology Centre (Imperial College School of Medicine, London, United Kingdom).

Platelet preparation. Platelets were isolated from peripheral blood of normal healthy volunteers. In brief, blood was collected into a prewarmed syringe containing sodium citrate $(105 \mathrm{mmol} / \mathrm{L})$ in a $1: 10$ ratio and $2.0 \%$ dextrose by antecubital venipuncture in the absence of a tourniquet. Epoprostenol (prostacyclin) was added at a dose of $1 \mu \mathrm{mol} / \mathrm{L}$ and platelet-rich plasma was decanted off after an initial spin at $1100 \mathrm{rpm}$ for 10 minutes. Platelet-rich plasma was recentrifuged at $2100 \mathrm{rpm}$ for 12 minutes at room temperature and the resulting pellet gently resuspended at $2 \times 10^{8}$ platelets per milliliter in platelet buffer containing the following: $\mathrm{NaCl}, 140 \mathrm{mmol} / \mathrm{L} ; \mathrm{KCl}, 5 \mathrm{mmol} / \mathrm{L} ; \mathrm{MgCl}_{2}, 0.4 \mathrm{mmol} / \mathrm{L}$; $\mathrm{NaHCO}_{3}, 25 \mathrm{mmol} / \mathrm{L}$; D-glucose, $5 \mathrm{mmol} / \mathrm{L} ; 0.2 \%$ bovine serum albumin; and HEPES buffer, $20 \mathrm{mmol} / \mathrm{L}$; pH 7.4. Platelets were incubated at $37^{\circ} \mathrm{C}$ for 30 minutes before use and were not activated according to the following criteria: (1) platelet size less than $30 \mu \mathrm{L}$, assessed by a Sysmex counter (Sysmex, Milton Keynes, United Kingdom), and (2) absence of P-selectin surface expression, assessed by fluorescence-activated cell sorter analysis (Coulter Electronics Ltd, Bedford, United Kingdom) with monoclonal anti-P-selectin antibody AK-4 (Sigma) (fluorescent intensity of AK-4 staining relative to isotype matched control antibody $=1.0$, compared with $>7.0$ after platelet activation). Absence of clotting factor contamination was assessed by lack of detectable antithrombin III $(<0.01 \mathrm{U} / \mathrm{mL})$, protein $\mathrm{C}(<0.01 \mathrm{U} / \mathrm{mL})$, and protein $\mathrm{S}(<0.01$ $\mathrm{U} / \mathrm{mL}$ ) in the platelet suspension.

Platelet aggregation. Platelet aggregation was studied with the use of a Clandon Aggrecorder PA3220 device (Clandon YSI Ltd, Farnborough, United Kingdom). In brief, $1 \times 10^{8}$ platelets were resuspended in $450 \mu \mathrm{L}$ platelet buffer adjusted to a 1.2$\mathrm{mmol} / \mathrm{L}$ concentration of $\mathrm{CaCl}_{2}$ and containing a $100-\mu \mathrm{g} / \mathrm{mL}$ concentration of fibrinogen before use. Aprotinin $(50,100$, or $160 \mathrm{KIU} / \mathrm{mL})$ or PAR1 antagonist peptides $(500 \mu \mathrm{mol} / \mathrm{L}$ FLLRN or $300 \mu \mathrm{mol} / \mathrm{L}$ MSRPACN) were added immediately before platelet agonists at the following final concentrations: thrombin, $1 \mathrm{nmol} / \mathrm{L}$; trypsin, $1 \mu \mathrm{mol} / \mathrm{L}$; collagen, 50 to 100 $\mu \mathrm{g} / \mathrm{mL}$; epinephrine, 2.5 to $10 \mu \mathrm{g} / \mathrm{mL}$; ADP, 1 to $15 \mu \mathrm{mol} / \mathrm{L}$; PMA, $100 \mathrm{nmol} / \mathrm{L}$; or SFLLRN, $100 \mu \mathrm{mol} / \mathrm{L}$.

Intraplatelet $\mathrm{Ca}^{2+}$ levels. Platelets were loaded with fura2 AM (Molecular Probes Inc, Eugene, Ore) for 45 minutes at $37^{\circ} \mathrm{C}$, as previously described. ${ }^{23}$ Fura-2-loaded platelets were adjusted to $2 \times 10^{8}$ per milliliter. Measurements of intra- 
A

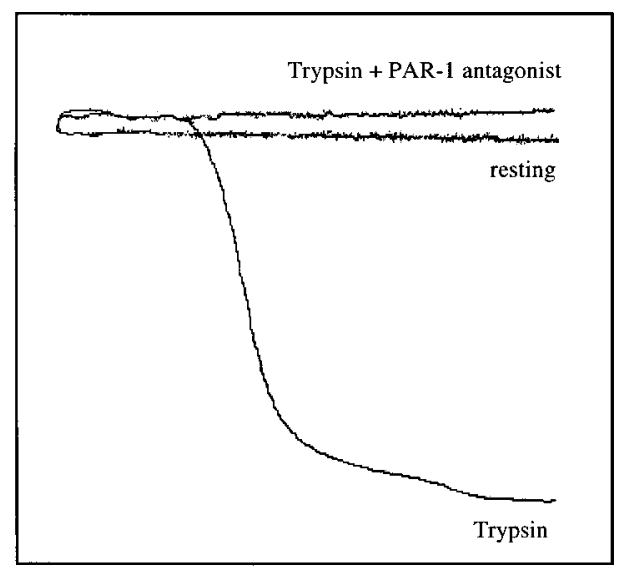

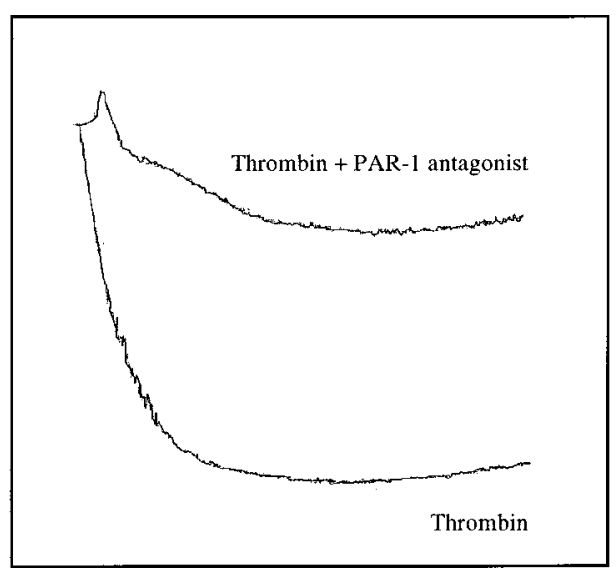

Fig 1. PAR1 dependence of trypsin-induced (A) and thrombin-induced platelet aggregation (B). Washed platelets $\left(1 \times 10^{8}\right)$ were pretreated with the PAR1 antagonistic peptide, FLLRN (500 $\mu \mathrm{mol} / \mathrm{L})$, immediately before the addition of trypsin $(1 \mu \mathrm{mol} / \mathrm{L})$ or thrombin $(1 \mu \mathrm{nmol} / \mathrm{L})$. Aggregometry traces from an individual experiment are shown, representative of $n=4-6$ for each experimental condition.

cellular calcium were obtained by measuring fura- 2 fluorescence at 340-nm excitation and 510-nm emission with an LS 50 B spectrofluorometer (Perkin-Elmer, Beaconsfield, United Kingdom). Aprotinin or PAR1 antagonist peptides were added at the final concentrations indicated above until a steady baseline reading was obtained. Platelet agonists were added at the same concentrations as used in aggregometry, after which fluorescence tracings were obtained. Intraplatelet $\mathrm{Ca}^{2+}$ fluxes were determined by subtracting the baseline from peak levels and calibrating to a known standard. Results are expressed as the $\mathrm{Ca}^{2+}$ flux in nanomoles per liter.

Platelet microaggregation in whole blood. Platelet microaggregation in whole blood was measured by counting the number of single platelets remaining after aggregation. ${ }^{24}$ Then, $250 \mu \mathrm{L}$ of peripheral blood was anticoagulated with citrate, diluted in a $250-\mu \mathrm{L}$ concentration of buffer in the presence or absence of aprotinin at $160 \mathrm{KIU} / \mathrm{mL}$, and single platelet counts were performed with a Sysmex counter (Sysmex) after the addition of thrombin $(1 \mathrm{nmol} / \mathrm{L})$, trypsin ( $1 \mu \mathrm{mol} / \mathrm{L})$, epinephrine $(2.5 \mu \mathrm{mol} / \mathrm{L})$, or ADP $(2 \mu \mathrm{mol} / \mathrm{L})$. Platelets that had formed either microaggregates or macroaggregates are excluded from the single-platelet gate, and the percentage of platelets that had aggregated is expressed relative to the platelet count before agonist addition.

Statistics. Platelet aggregation and intraplatelet $\mathrm{Ca}^{2+}$ flux data were analyzed by a 1-way analysis of variance with a Newman-Keuls post test (GraphPad Software Inc, San Diego, Calif).

\section{Results}

PAR1 dependence of platelet aggregation induced by trypsin and thrombin. Trypsin has been shown to possess agonist activity for both PAR1 and
PAR2, ${ }^{13,25,26}$ making it an ideal reagent with which to examine PAR1-specific actions on platelets that only express functional PAR1 and PAR4. ${ }^{15,27}$ Confirmation of this fact is shown in Fig 1, A, which demonstrates complete inhibition of trypsin-induced platelet aggregation in washed platelets by the competitive PAR 1 antagonist peptide, FLLRN. Aggregation induced by trypsin was consistently slower than that induced with thrombin, in keeping with the known lower affinity of trypsin for PAR1. ${ }^{13,25}$ Aggregation was rapidly induced by a $1-\mathrm{nmol} / \mathrm{L}$ dose of thrombin and was typically inhibited $70 \%$ to $100 \%$ by PAR1 antagonist peptide (Fig 1, B). Although PAR4 is not activated at this concentration of thrombin, ${ }^{27}$ residual aggregation may be explained by the action of thrombin on non-PAR receptors, such as glycoprotein Ib. ${ }^{21}$ The specificity of the PAR1 antagonist peptide was confirmed by a lack of effect on platelet aggregation induced by collagen, epinephrine, and ADP (data not shown). Similar results were obtained with a distinct PAR1 antagonist peptide, MSRPACN, isolated from a random phage display library $^{22}$ (data not shown). These data therefore demonstrate PAR1-specific platelet activation by trypsin and a primary role for PAR1 in thrombin-induced platelet aggregation.

Aprotinin inhibits platelet aggregation induced by trypsin and thrombin. Fig $2, A$ and $B$, shows the effect of aprotinin in increasing concentrations on platelet aggregation induced by trypsin and thrombin. Aprotinin completely inhibited trypsin-induced platelet aggregation at 100 and $160 \mathrm{KIU} / \mathrm{mL}$, concentrations 
A

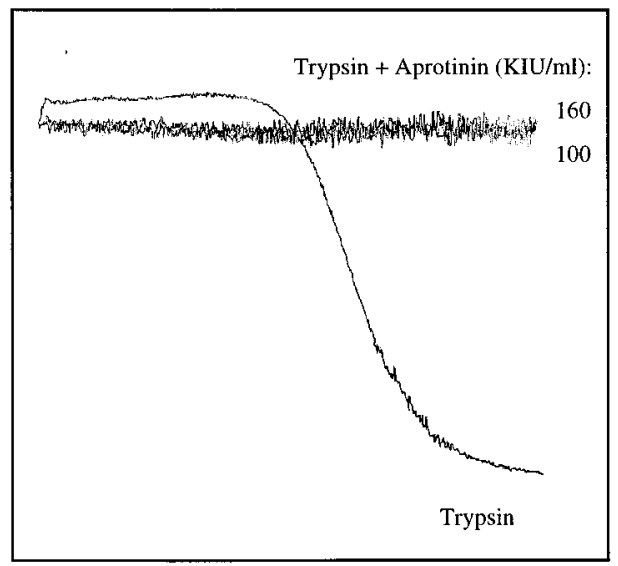

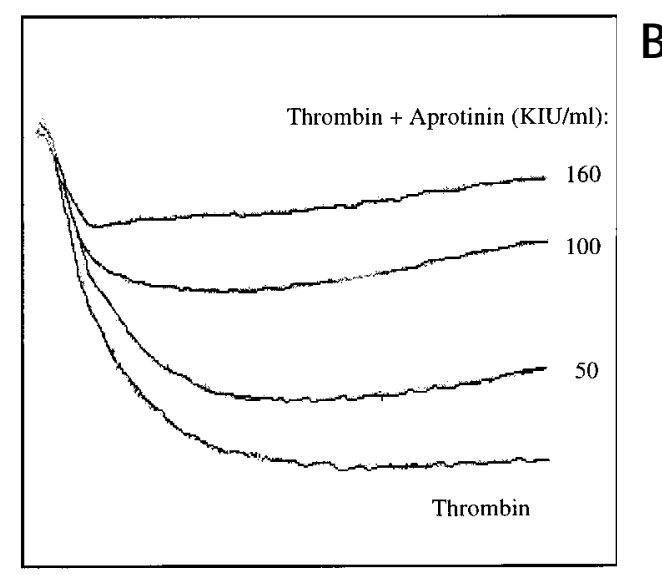

Fig 2. Aprotinin inhibits platelet aggregation induced by trypsin (A) and thrombin (B). Platelets were pretreated with aprotinin at 50-, 100-, or 160-KIU/ml doses immediately before the addition of trypsin or thrombin. Aggregometry traces from an individual experiment are shown, representative of $n=5-12$ for each experimental condition.
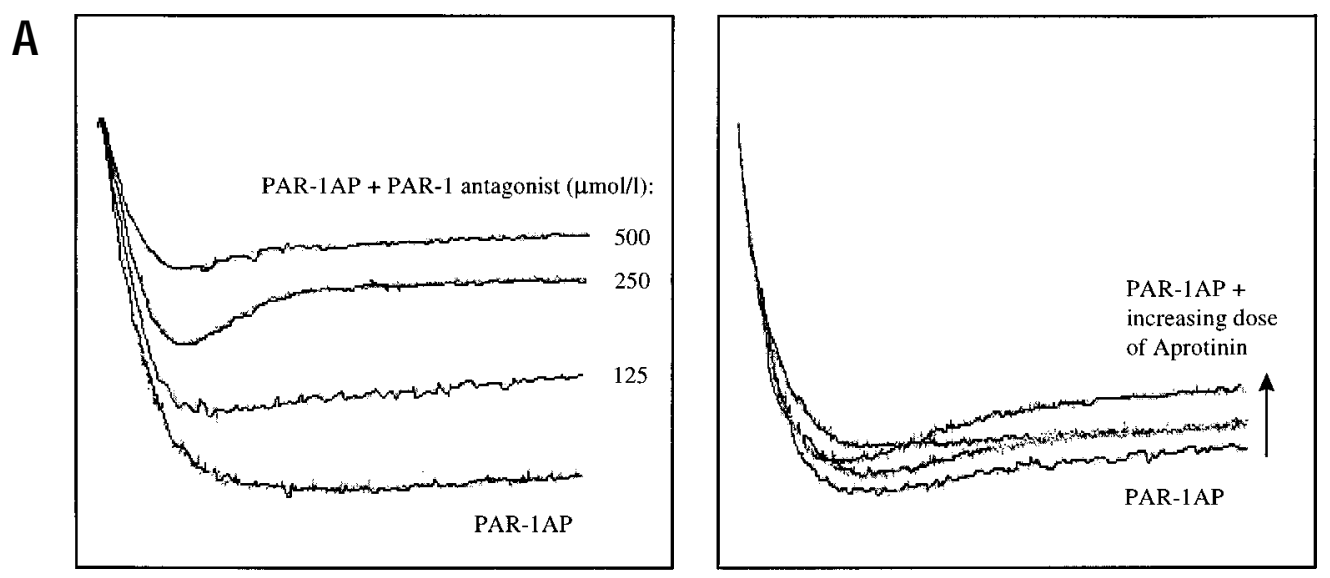

B

Fig 3. Aprotinin does not inhibit platelet aggregation induced by SFLLRN. Platelet aggregation was induced by the PAR1 agonist peptide $(P A R-1 A P)$, SFLLRN $(100 \mu \mathrm{mol} / \mathrm{L})$, in the presence of antagonistic peptide, FLLRN (125-500- $\mu \mathrm{mol} / \mathrm{L}$ doses) (A), or aprotinin (50-160-KIU/mL doses) (B). Individual traces representative of $n=4$ similar experiments are shown.

that are relevant to cardiovascular surgery. Thrombininduced platelet aggregation was also significantly inhibited by aprotinin, albeit incompletely (mean \pm SD inhibition from 6 donors, $42.6 \% \pm 21.6 \%$ at 50 $\mathrm{KIU} / \mathrm{mL}(P<.05), 61.0 \% \pm 25.2 \%$ at $100 \mathrm{KIU} / \mathrm{mL}(P$ $<.05)$, and $86.6 \% \pm 8.9 \%$ at $160 \mathrm{KIU} / \mathrm{mL}(P<.001))$. These results therefore demonstrated that aprotinin strongly inhibited PAR1-mediated platelet aggregation induced by both trypsin and thrombin.

The site of aprotinin action localizes to the proteolytic cleavage event in PAR1 activation. The PAR1 agonist peptide, SFLLRN, triggers activation in the absence of receptor cleavage by mimicking the tethered ligand of PAR1. Fig 3 demonstrates that platelet aggregation induced through SFLLRN was inhibited by the competitive PAR1 antagonist peptide, FLLRN, but not by aprotinin. The lack of complete inhibition with antagonist is consistent with results in a previous report $^{18}$ (Fig 3, A). Aprotinin failed to inhibit platelet aggregation with respect to SFLLRN, even when used at high concentrations up to $400 \mathrm{KIU} / \mathrm{mL}$ (Fig 3, B). At this concentration, aprotinin completely inhibited thrombin-induced platelet aggregation. An inability to block SFLLRN-induced aggregation localized the site 
A

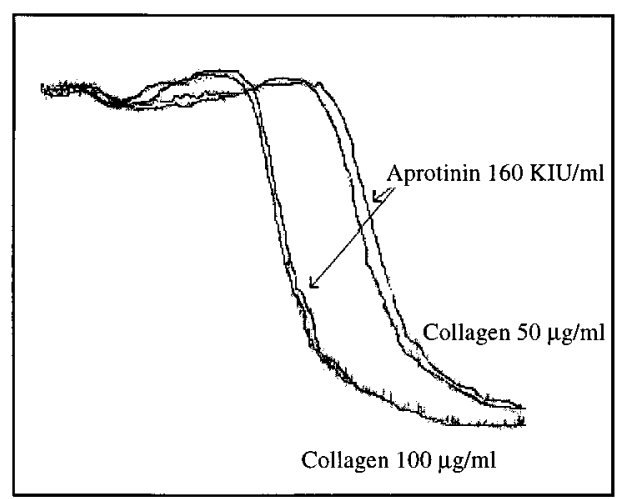

C

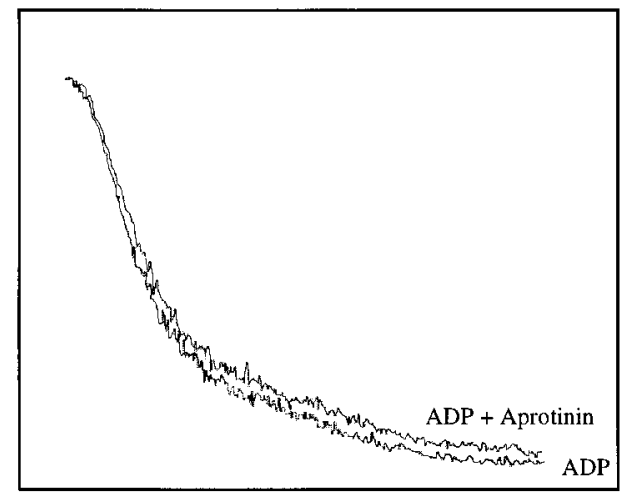

E

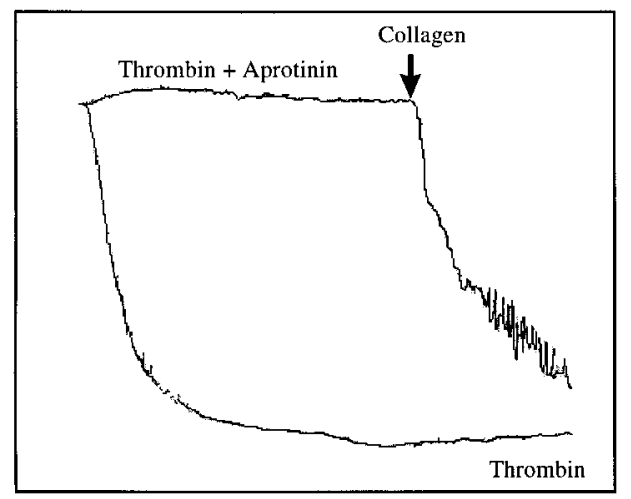

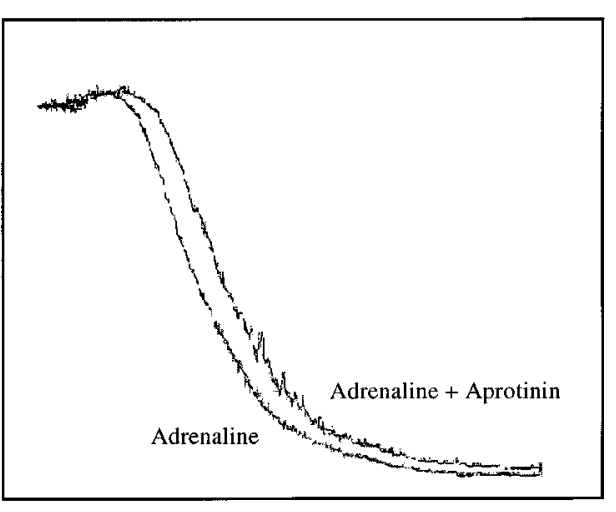

B

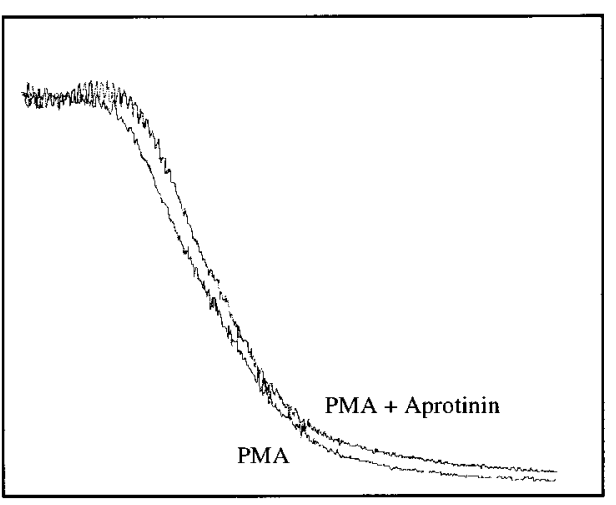

D

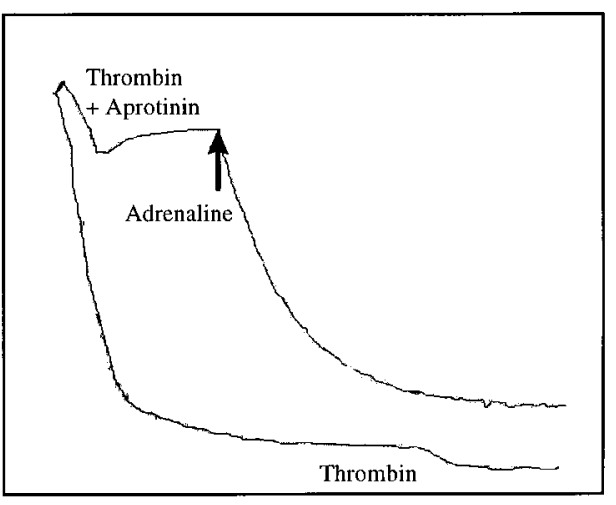

Fig 4. Aprotinin does not inhibit proteolysis-independent pathways of platelet activation. Platelets were pretreated with aprotinin, $160 \mathrm{KIU} / \mathrm{mL}$, immediately before the addition of collagen (50 and $100 \mu \mathrm{g} / \mathrm{mL})(\mathbf{A})$, epinephrine (Adrenaline) $(2.5 \mu \mathrm{mol} / \mathrm{L})(\mathbf{B}), \operatorname{ADP}(2 \mu \mathrm{mol} / \mathrm{L})(\mathbf{C})$, and PMA (100 nmol/L) (D). $\mathbf{E}$ and $\mathbf{F}$ depict aggregometry traces of platelets pretreated with thrombin and aprotinin, before and after the addition of collagen $(100 \mu \mathrm{g} / \mathrm{mL})(\mathbf{E})$ or epinephrine $(5$ $\mu \mathrm{mol} / \mathrm{L})(\mathbf{F})$ marked by an arrow. Individual traces representative of $n=3-5$ experiments are shown.

of action of aprotinin proximal to the binding of tethered ligand to the PAR1 receptor. These results strongly suggested that blockade of trypsin and thrombininduced aggregation by aprotinin was due to inhibition of receptor proteolysis, therefore preventing exposure of the tethered ligand and signal transduction.
Aprotinin does not inhibit platelet aggregation induced through collagen, epinephrine, ADP, or PMA. The specificity of aprotinin action was next examined with the use of the nonproteolytic agonists collagen, epinephrine, ADP, and PMA (Fig 4, A-D). Aprotinin did not block platelet aggregation in 
response to any of these stimuli and was therefore specific to the actions of PAR-dependent agonists such as thrombin and trypsin. The lack of effect of aprotinin on PMA-induced aggregation, a direct-acting protein kinase $\mathrm{C}$ agonist, demonstrated that aprotinin had no effect on protein kinase $\mathrm{C}$ or downstream signaling pathways. These experiments also ruled out the possibility that aprotinin was blocking a common distal event in aggregation, such as the binding of fibrinogen to glycoprotein IIb/IIIa. We next examined whether the antithrombotic actions of aprotinin described in Fig 2, $B$, could affect subsequent activation of platelets by other agonists. In these experiments, platelets were first treated with thrombin and aprotinin and then restimulated with collagen or epinephrine. Fig $4, E$ and $F$, demonstrates that inhibition of the thrombin pathway by aprotinin does not prevent subsequent aggregation from occurring in response to collagen or epinephrine. The importance of this observation, particularly with respect to collagen, which is likely to play an important role in the formation of hemostatic plugs at sites that are cut or approximated during cardiac surgery, is that it reveals a simultaneous antithrombotic but not antihemostatic property of aprotinin.

Aprotinin inhibits intraplatelet $\mathrm{Ca}^{2+}$ fluxes induced by thrombin and trypsin. The mechanism of action of aprotinin was further investigated by studying intraplatelet $\mathrm{Ca}^{2+}$ mobilization in response to proteolytic and nonproteolytic platelet agonists. The $\mathrm{Ca}^{2+}$ trace in Fig 5, $A$, illustrates a typical intraplatelet $\mathrm{Ca}^{2+}$ flux in response to thrombin, occurring within 5 seconds of thrombin addition. Fig 5, $B$, demonstrates that prior addition of aprotinin completely abolished $\mathrm{Ca}^{2+}$ fluxes in response to thrombin but had no effect on subsequent activation through the non-PAR agonist epinephrine. Furthermore, although aprotinin blocked $\mathrm{Ca}^{2+}$ fluxes to thrombin, it had no effect on subsequent stimulation by the proteolysis-independent PAR1 agonist peptide, SFLLRN (Fig 5, C). These results demonstrate clearly that the action of aprotinin was not directed at signaling components of the PAR1 receptor complex but was likely directed at the proteolytic cleavage event of PAR1 activation. Fig $6, A$ to $D$, summarizes intraplatelet $\mathrm{Ca}^{2+}$ flux data with the use of the platelet agonists trypsin, thrombin, SFLLRN, and epinephrine, respectively. Whereas aprotinin significantly reduced peak intraplatelet $\mathrm{Ca}^{2+}$ levels in response to trypsin $(P$ $=.008)$ and thrombin $(P=.008)$, it had no significant effect on stimulation by SFLLRN $(P=.1)$ or epinephrine $(P=.1)$.

Aprotinin specifically inhibits trypsin and thrombin-induced platelet aggregation in whole blood. To extend the clinical relevance of our findings, which

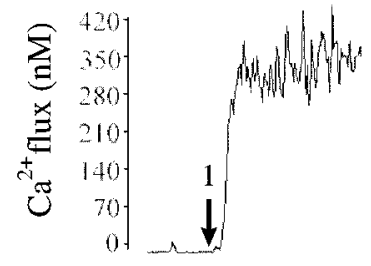

1 Thrombin

2 Thrombin + Aprotinin

3 Adrenaline

4 PAR-1AP
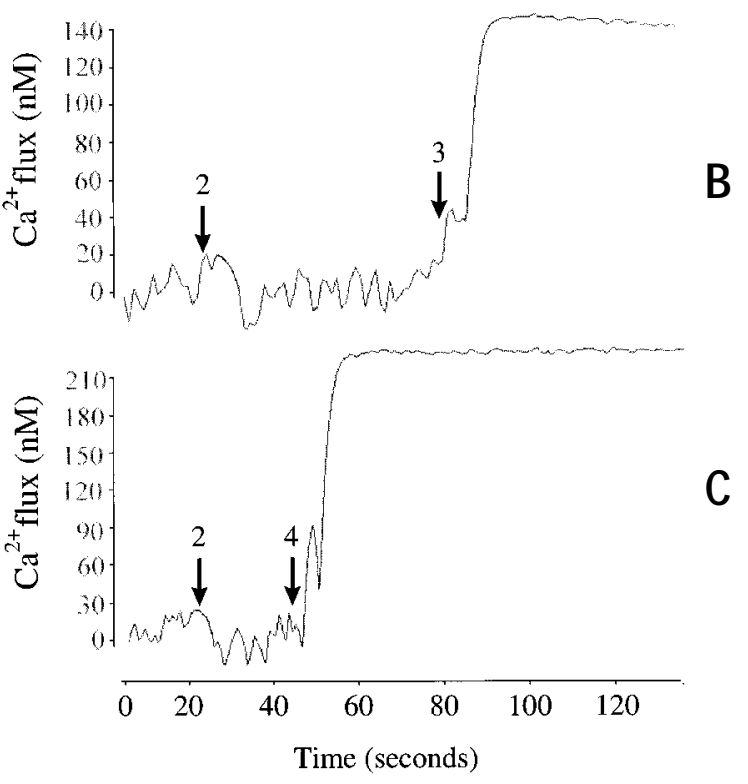

Fig 5. Effect of aprotinin on intraplatelet $\mathrm{Ca}^{2+}$ fluxes induced by thrombin, epinephrine (Adrenaline), or SFLLRN. Free intracellular $\mathrm{Ca}^{2+}$ levels were measured in fura-2-loaded platelets $\left(1 \times 10^{8}\right)$ by fluorimetry. A, Steady baseline reading and intraplatelet $\mathrm{Ca}^{2+}$ flux after the addition of thrombin (1 $\mathrm{nmol} / \mathrm{L}$, arrow). $\mathbf{B}$, Inhibition of thrombin-induced $\mathrm{Ca}^{2+}$ fluxes by aprotinin $(160 \mathrm{KIU} / \mathrm{mL})$ but subsequent $\mathrm{Ca}^{2+}$ flux generated in response to epinephrine $(5 \mu \mathrm{mol} / \mathrm{L})$. $\mathbf{C}$, Inhibition of thrombin-induced $\mathrm{Ca}^{2+}$ fluxes by aprotinin and subsequent flux in response to the PAR1 agonist peptide (PAR-1AP), SFLLRN $(100 \mu \mathrm{mol} / \mathrm{L})$. Individual traces representative of $n$ $=3$ experiments are shown.

used washed platelets, we repeated the basic observations in whole blood using microaggregation as a measure of platelet activation. Fig 7 demonstrates that aprotinin inhibited formation of platelet microaggregates induced by thrombin and trypsin but had no effect on epinephrine- or ADP-induced aggregation.

\section{Discussion}

We have demonstrated that trypsin is a selective proteolytic activator of PAR1 in washed platelets and that aprotinin completely blocked this mechanism of platelet activation. Activation by thrombin in a $1-\mathrm{nmol} / \mathrm{L}$ concentration has been previously shown to be primarily mediated through PAR1, ${ }^{20,27}$ and this response was 

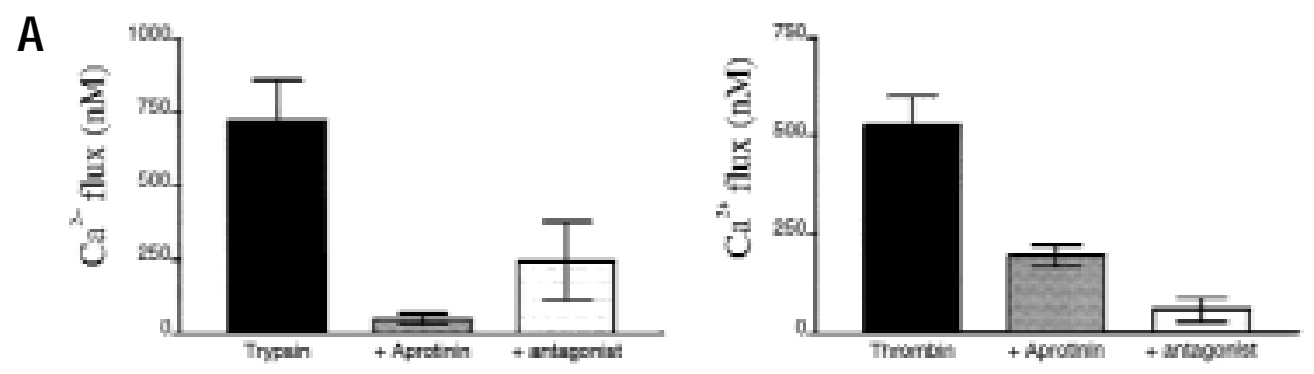

B
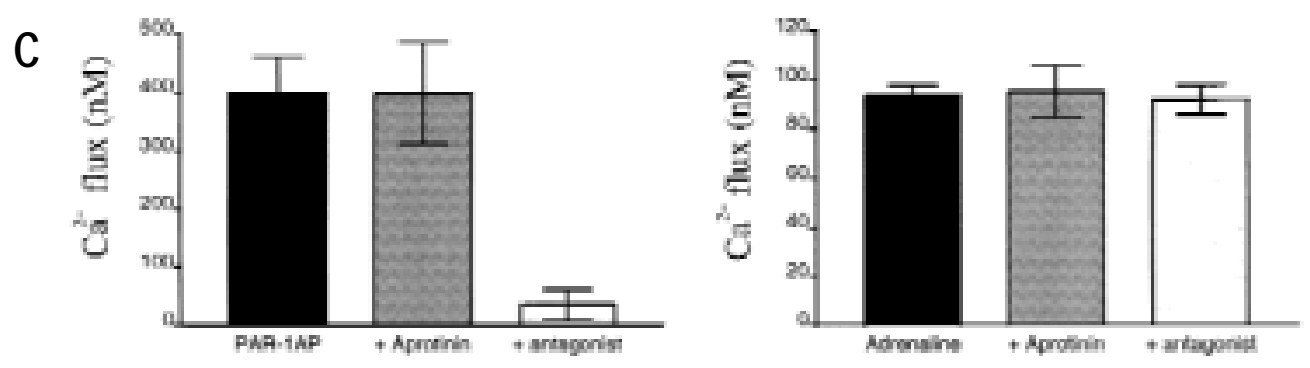

Fig 6. Effects of aprotinin and PAR1 antagonist peptide on $\mathrm{Ca}^{2+}$ fluxes in response to trypsin (A), thrombin (B), SFLLRN (C), and epinephrine (adrenaline) (D) $\mathrm{Ca}^{2+}$ fluxes were calculated by subtracting the baseline from free intraplatelet $\mathrm{Ca}^{2+}$ readings after addition of trypsin $(1 \mu \mathrm{mol} / \mathrm{L})$, thrombin $(1 \mathrm{nmol} / \mathrm{L})$, PAR-1 agonist peptide (SFLLRN, $100 \mu \mathrm{mol} / \mathrm{L}$ ), and epinephrine (Adrenaline, $5 \mu \mathrm{mol} / \mathrm{L}$ ). The figure depicts mean $\mathrm{Ca}^{2+}$ fluxes $\pm \mathrm{SD}$ in response to agonist only (black column), agonist + aprotinin $(160 \mathrm{KIU} / \mathrm{mL}$, shaded column), and agonist + antagonist peptide, FLLRN (500 $\mu \mathrm{mol} / \mathrm{L}$, open column $)$, from $\mathrm{n}=4-6$ experiments.

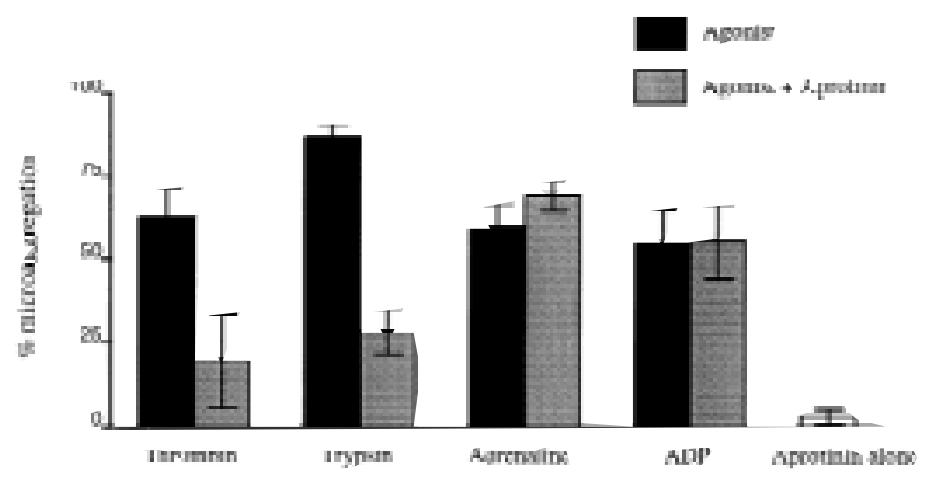

Fig 7. Specific inhibition by aprotinin of thrombin- and trypsin-induced microaggregation in whole blood. The effect of aprotinin $(160 \mathrm{KIU} / \mathrm{mL})$ on microaggregation in whole blood was studied in response to the proteolysisdependent agonists thrombin $(1 \mathrm{nmol} / \mathrm{L})$ and trypsin $(1 \mu \mathrm{mol} / \mathrm{L})$ and proteolysis-independent agonists epinephrine (Adrenaline, $2.5 \mu \mathrm{mol} / \mathrm{L})$ and $\mathrm{ADP}(2 \mu \mathrm{mol} / \mathrm{L})$. Results are expressed as the mean \pm SD percentage microaggregation from $\mathrm{n}=8-14$ for each experimental condition.

strongly inhibited by the synthetic PAR1 antagonist peptide and aprotinin at concentrations relevant to cardiac surgery. The absence of detectable clotting factors in the washed platelet preparation argues against the possibility that the effects of aprotinin were due to the targeting of unrelated solution phase substrates. Effects on platelet aggregation were mirrored by measurements of intraplatelet $\mathrm{Ca}^{2+}$ fluxes, therefore indicating that aprotinin inhibited a proximal event of platelet activation. Although aprotinin is likely to inhibit proteolytic 
activation of PAR4, we did not test the higher concentrations of thrombin necessary to activate this pathway and therefore cannot comment further on the effect of aprotinin on PAR4 or other nonproteolytic pathways of thrombin-induced aggregation. Additional relevance to our findings has been suggested by the recent demonstration that PAR1 is the primary mediator of thrombinstimulated procoagulant activity. ${ }^{28}$ Taken together, our data have shown that aprotinin exerts a significant antithrombotic effect in washed platelets by inhibiting platelet activation via PAR1.

The inhibitory mechanism of aprotinin was also specific, as platelet aggregation induced through non-PAR agonists collagen, epinephrine, ADP, and PMA was not blocked by aprotinin. This fact, together with $\mathrm{Ca}^{2+}$ flux data, supports a receptor-specific mechanism of action of aprotinin, upstream of PAR1 signaling. The clinical relevance of these findings was further extended by repeating basic observations in a study of microaggregation in whole blood. Since aprotinin did not inhibit PAR1 activation by the nonproteolytic agonist peptide, SFLLRN, the implication is that aprotinin acted directly to prevent the serine protease-mediated cleavage of the receptor and not on the PAR1 ligand binding site or on the signaling components of the PAR1 receptor complex.

Interestingly, blockade of thrombin-induced platelet aggregation by aprotinin did not prevent subsequent aggregation in response to collagen. These results are consistent with the clinical observation that aprotinin preserves platelet function during cardiopulmonary bypass, presumably by inhibiting platelet activation resulting from thrombin generation, yet does not prevent formation of hemostatic plugs at wound and suture sites where collagen is likely to be exposed. ${ }^{29-31}$ The antithrombotic but not antihemostatic properties of aprotinin we have described herein may have important implications for the controversy surrounding the potential prothrombotic effect of aprotinin when given to patients during coronary bypass surgery. Although the weight of clinical evidence does not favor a detrimental association between aprotinin use and loss of graft patency, surgeons' concerns over this issue have not fully been answered, as evidenced by the vigorous discussion prompted by the recent International Multicenter Aprotinin Graft Patency Experience (IMAGE) trial. ${ }^{7}$ The perception still exists that a powerful hemostatic agent such as aprotinin may lead to an increased risk of coronary vein graft occlusion. ${ }^{32} \mathrm{We}$ have always believed that this issue would be resolved when the mechanism of action of aprotinin was better understood. We have localized the in vitro mechanism of action of aprotinin on platelets to the inhibition of proteolysis of PAR1. Since PAR1 activation induced by thrombin is specifically blocked by aprotinin, concerns over a potential prothrombotic effect of aprotinin during coronary surgery may be unfounded.

We thank Dr Sussan Nourshargh for assistance with the intraplatelet calcium studies.

\section{REFERENCES}

1. van Oeveren W, Jansen NJ, Bidstrup BP, Royston D, Westaby S, Neuhof H, et al. Effects of aprotinin on hemostatic mechanisms during cardiopulmonary bypass. Ann Thorac Surg 1987;44:640-5.

2. Royston D, Bidstrup BP, Taylor KM, Sapford RN. Effect of aprotinin on need for blood transfusions after repeat open heart surgery. Lancet 1987;2:1289-91.

3. Dietrich W, Barankay A, Dilthey G, Henze R, Niekau E, Sebening F, et al. Reduction of homologous blood requirement in cardiac surgery by intraoperative aprotinin application: clinical experience in 152 cardiac surgical patients. Thorac Cardiovasc Surg 1989;37:92-8.

4. Blauhut B, Gross C, Necek S, Doran JE, Spath P, LundsgaardAnderson P. Effects of high-dose aprotinin on blood loss, platelet function, fibrinolysis, complement, and renal function after CPB. J Thorac Cardiovasc Surg 1991;101:958-67.

5. Peters DC, Noble S. Aprotinin: an update of its pharmacology and therapeutic use in open heart surgery and coronary artery bypass surgery. Drugs 1999;57:233-60.

6. Cosgrove DM 3d, Heric B, Lytle BW, Taylor PC, Novoa R, Golding LA, et al. Aprotinin therapy for reoperative myocardial revascularization: a placebo controlled study. Ann Thorac Surg 1992;54:1036-8

7. Alderman EL, Levy JH, Rich JB, Nili M, Vidne B, Schaff H, et al. Analyses of coronary graft patency after aprotinin use: results from the International Multicenter Aprotinin Graft Patency Experience (IMAGE) trial. J Thorac Cardiovasc Surg 1998;116:716-30.

8. Royston D. Aprotinin versus lysine analogues: the debate continues. Ann Thorac Surg 1998;65:S9-19.

9. Boisclar MD, Lane DA, Philippou H, Sheikh S, Hunt B. Thrombin production, inactivation and expression during open heart surgery measured by assays for activation fragments including new ELISA for prothrombin fragment $\mathrm{F} 1+2$. Thromb Haemost 1993;70:253-8.

10. Brister SJ, Ofosu FA, Buchanan MR Thrombin generation during cardiac surgery: Is heparin the ideal anticoagulant? Thromb Haemost 1993;70:259-62.

11. Ferraris VA, Ferraris SP, Singh A, Fuhr W, Koppel D, McKenna $\mathrm{D}$, et al. The platelet thrombin receptor and postoperative bleeding. Ann Thorac Surg 1998;65:352-8.

12. Angelini GD. Saphenous vein graft failure: etiologic considerations and strategies for prevention. Curr Opin Cardiol 1992; 7:939-44.

13. Vu TK, Hung DT, Wheaton VI, Coughlin SR. Molecular cloning of a functional thrombin receptor reveals a novel proteolytic mechanism of receptor activation. Cell 1991;64:1057-68.

14. Ji TH, Grossmann M, Ji I. G protein-coupled receptors I. Diversity of receptor ligand interactions. J Biol Chem 1998;272:17299-302. 
15. Coughlin SR. How the protease thrombin talks to cells. Proc Natl Acad Sci U S A 1999;96:11023-7.

16. Vu TK, Wheaton VI, Hung DT, Charo I, Coughlin SR. Domains specifying thrombin-receptor interaction. Nature 1991;353:674-7.

17. Lerner DJ, Chen M, Tram T, Coughlin SR. Agonist recognition by proteinase-activated receptor 2 and thrombin receptor: importance of extracellular loop interactions for receptor function. $\mathrm{J}$ Biol Chem 1996;271:13943-7.

18. Vassallo RR Jr, Kieber-Emmons T, Cichowski K, Brass LF. Structure-function relationships in the activation of platelet thrombin receptors by receptor-derived peptides. J Biol Chem 1992;267:6081-5.

19. Scarborough RM, Naughton MA, Teng W, Hung DT, Rose J, Vu TK, et al. Tethered ligand agonist peptides: structural requirements for thrombin receptor activation reveal mechanism of proteolytic unmasking of agonist function. J Biol Chem 1992;267:13146-9.

20. Kahn ML, Zheng YW, Huang W, Bigornia V, Zeng D, Moff S, et al. A dual thrombin receptor system for platelet activation. Nature 1998;394:690-4.

21. De Marco L, Mazzucato M, Masotti A, Ruggeri ZM. Localisation and characterisation of an $\alpha$-thrombin binding site on platelet glycoprotein Ib $\alpha$. J Biol Chem 1994;269:6478-84.

22. Doorbar J, Winter G. Isolation of a peptide antagonist to the thrombin receptor using phage display. J Mol Biol 1994;244:361-9.

23. Nourshargh S, Perkins JA, Showell HJ, Matsushima K, Williams TJ, Collins PD. A comparative study of the neutrophil stimulatory activity in vitro and pro-inflammatory properties in vivo of 72 amino acid and 77 amino acid IL-8. J Immunol 1992;148:106-11.

24. Storey RF, Wilcox RG, Heptinstall S. Differential effects of glycoprotein IIb/IIIa antagonists on platelet microaggregate and macroaggregate formation and effect of anticoagulant on antagonist potency: implications for assay methodology and comparison of different agonists. Circulation 1998;98:1616-21.

25. Santulli RJ, Derian CK, Darrow AL, Tomko KA, Eckardt AJ, Seiberg M, et al. Evidence for the presence of a protease-activated receptor distinct from the thrombin receptor in human keratinocytes. Proc Natl Acad Sci U S A 1995;92:9151-5.

26. Molino M, Woolkalis MJ, Reavey-Cantwell J, Pratico D, Andrade-Gordon P, Barnathan ES, et al. Endothelial cell thrombin receptors and PAR2: two protease-activated receptors located in a single cellular environment. J Biol Chem 1997;272:11133-41.

27. Kahn ML, Nakanishi MM, Shapiro MJ, Ishihara H, Coughlin SR. Protease-activated receptors 1 and 4 mediate activation of human platelets by thrombin. J Clin Invest 1999;103:879-87.

28. Andersen H, Greenberg DL, Fujikawa K, Xu W, Chung DW, Davie EW. Protease-activated receptor 1 is the primary mediator of thrombin-stimulated platelet procoagulant activity. Proc Natl Acad Sci U S A 1999;96:11189-93.

29. Wildevuur CR, Eijsman L, Roozendaal KJ, Harder MP, Chang M, van Oeveren W. Platelet preservation during cardiopulmonary bypass with aprotinin. Eur J Cardiothorac Surg 1989;3:533-7.

30. Primack C, Walenga JM, Koza MJ, Shankey TV, Pifarre R. Aprotinin modulation of platelet activation in patients undergoing cardiopulmonary bypass operations. Ann Thorac Surg 1996;61:1188-93.

31. Shigeta O, Kojima H, Jikuya T, Terada Y, Atsumi N, Sakakibara $\mathrm{Y}$, et al. Aprotinin inhibits plasmin-induced platelet activation during cardiopulmonary bypass. Circulation 1997;96:569-74.

32. Westaby S, Katsumata T. Editorial: Aprotinin and vein graft occlusion-the controversy continues. J Thorac Cardiovasc Surg 1998;116:731-3 